\title{
ATMOSPHERIC OZONE PROFILES DURING VASYLKIV OIL BURNING EPISODE
}

\author{
A.Shavrina ${ }^{1}$, A.Veles ${ }^{1}$, G.Milinevsky $^{1,2}$, A.Grytsai ${ }^{2}$, A.Liptuga $^{3}$, V.Kyslyi $^{3}$, Ya.Romanyuk $^{1}$ \\ ${ }^{1}$ Main Astronomical Observatory of National Academy of Scienses of Ukraine, \\ Kyiv, Ukraine \\ ${ }^{2}$ Taras Shevchenko National University of Kyiv, Kyiv, Ukraine \\ ${ }^{3}$ V.E.Lashkaryov Institute of Semiconductor Physics of National Academy of Scienses \\ of Ukraine, Kyiv, Ukraine
}

ABSTRACT. Ground-based Fourier Transform Infrared spectrometer (FTIR) observations have been used for study stratosphere/troposphere ozone vertical distribution during Vasylkiv (near Kyiv, Ukraine) incident of petroleum storage burning in June 8-14, 2015.

\section{Introduction}

The study of fire-oil incidents influence on atmospheric ozone is important because the ozone content in the Earth's atmosphere is of critical importance. The stratospheric ozone layer protects all living organisms on Earth from the harmful effects of excessive ultraviolet solar irradiation. Scientists consider organic compounds contained bromine, chlorine as substances that destroy the ozone layer. The ozone depleting potential (ODP) is the paremeter which allow estimate the harmful properties for ozone quantitatively. The higher the ODP of a certain substance, the more dangerous it is to the ozone layer. The highest ODP, reaching 12, have gallons, organic gases, which are used, for example, for fire extinguishing. On the contrary, high concentrations of ozone in the lower part of the atmosphere, the troposphere, ozone acts as health hazardous air pollutant.Tropospheric ozone is very toxic to air breathing organisms like humans and corrosive to the leaf surfaces of plants.

Total ozone column (TOC) is a parameter which characterizes total number of ozone molecules in the atmospheric column over observation site. This atmospheric parameter is traditionally measured in Dobson Units (DU): 1 DU corresponds to gas layer with thickness in $0.01 \mathrm{~mm}$ under standard atmospheric pressure and temperature. TOC is determined by many photochemical and dynamical processes both of stratospheric and tropospheric origin.

Ozone levels in the middle latitudes of the Northern Hemisphere are strongly dependent on the Brewer-Dobson circulation (Butchart, 2014), which causes air transport from tropic regions. Time of the seasonal ozone maximum is changed with longitude (Peters et al., 2008). Over Ukraine, the maximum is usually registered during early spring with total ozone values being equal 400-450 DU (Evtushevsky et al., 2014). During the next months, the TOC levels decrease with a minimum existing in October-November when total ozone could be only 280-290 DU or even lower. Short-term total ozone variations are also observed. In particular, a TOC decrease is frequently registered under anticyclone conditions with high pressure and, respectively, TOC rises during cyclone activity with low pressure.

Total ozone could be changed due to tropospheric influence of the anthropogenic origin. It is known about TOC variations during Persian Gulf War in 1991 (Herring and Hobbs, 1992). The changes were caused by oil fires in Kuwait (Herring et al., 1996). The effect is described as a complicated phenomenon. In these events additional tropospheric was created close to the fire regions. On the contrary, at the edge of the fire area the total ozone values were lower than usually.

In June 8, 2015, significant oil burning began near Vasylkiv city $\left(48.98^{\circ} \mathrm{N}, 31.32^{\circ} \mathrm{E}\right)$ close to Kyiv (Ukraine). It is continued during a week with penetrating large number of smoke particles into the atmosphere. Correspondingly, a question on a possible influence of the fire onto ozone levels over the surrounding area is matter of interest. The methods of analysis and the picture of the phenomenon are briefly described in the next parts of the paper.

\section{Spectral modeling and analysis}

The estimates of total ozone columns in the Earth's atmosphere were obtained using a simulation of the ozone absorption spectrum at $9.6 \mu$ with the radiative transfer code MODTRAN4.3 (Bernstein et al., 1996). The program calculates the transmission of electromagnetic radiation of solar origin through the modelled atmosphere and its subsequent reflection on the surface in the frequency range from 1 to $50000 \mathrm{~cm}^{-1}$. The program employs a twoparameter (temperature and pressure) model of molecular spectral absorption, which is calculated with the molecular database HITRAN (http://www.cfa.harvard.edu/hitran/) containing molecular spectral absorption lines. To calcu- 
late the band model, data for 12 light gaseous molecules $\left(\mathrm{H}_{2} \mathrm{O}, \mathrm{CO}_{2}, \mathrm{O}_{3}, \mathrm{CO}, \mathrm{CH}_{4}, \mathrm{O}_{2}, \mathrm{NO}, \mathrm{SO}_{2}, \mathrm{NO}_{2}, \mathrm{~N}_{2} \mathrm{O}, \mathrm{NH}_{4}\right.$ and $\mathrm{HNO}_{3}$ ) from the HITRAN database were used, and for heavy molecules - CFC (9 molecules) and $\mathrm{CLONO}_{2}$, $\mathrm{HNO}_{4}, \mathrm{CCl}$ and $\mathrm{N}_{2} \mathrm{O}_{5}$ the calculated absorption cross section (see [Bernstein et al., 1996]) were applied. The calculations were performed in the approximation of local thermodynamic equilibrium (LTE) for the moderate spectral resolution of $2 \mathrm{~cm}^{-1}$ which corresponds almost exactly to our observed spectra. The model parameters have been calculated by us using the database HITRAN-2004 (Rothman et al., 2005). To construct the apriori atmospheric profiles of ozone, temperature and water vapor were employed here (i) the observation of surface ozone concentrations as measured by the ground based ultraviolet ozonometer TEI-49i that is located near to the Fourier spectrometer detecting breathing-level ozone, (ii) data of the NASA Atmospheric Infrared Sounder (AIRS) satellite instrument (http://avdc.gsfc.nasa.gov/Data/AIRS/) onboard of the NASA EOS-Aqua satellite. A detailed description of our method for determining tropospheric and stratospheric concentrations of ozone can be found in (Shavrina et al., 2007, Shavrina et al., 2008). The result of the analysis is the best fit of the model spectrum to the observed spectra of the ozone band, from which we obtained the best estimates of the tropospheric vertical profiles of ozone, the total column amount of ozone in the troposphere and finally the total column amount of ozone in the atmosphere.

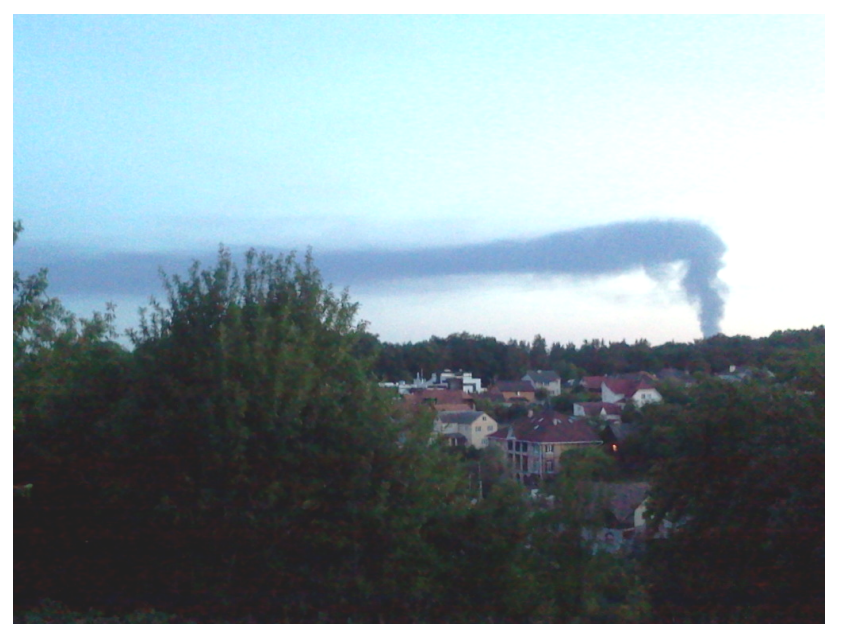

Figure 1: Smoke from oil burning near Vasylkiv on the evening of June 8, 2015.

\section{Results}

Total ozone is measured in Kyiv-Goloseyev station located at Main Astronomical Observatory $\left(50.36^{\circ} \mathrm{N}\right.$, $30.50^{\circ} \mathrm{E}$, altitude $206 \mathrm{~m}$ ) in the southern part of Kyiv. Total ozone measurements are carried out with Dobson spectrophotometer every day. To retrieve ozone vertical profiles, ground-based Fourier Transform Infrared spectrometer (FTIR) observations are realized under good weather conditions. The FTIR observations have been used to study the stratosphere and troposphere ozone vertical distribution during Vasylkiv incident with petroleum storage burning in June 8-14, 2015 (Fig. 1). The MODTRAN4 modeling of $\mathrm{O}_{3}(9.6 \mu)$ absorption band profile and FTIR measurements allow to analyze the ozone profiles. A noticeable decrease of total ozone (to values below 300 DU) was registered 13 June at KyivGoloseyev GAW station 498 (Milinevsky et al. 2012) after the wind was directed from Vasylkiv to Kyiv (Fig. 2). A distance between the burning point and the observational station is equal to $25 \mathrm{~km}$.

Aura-OMI data for June 2015 have also exhibited ozone decrease in June $12-13$ with a minimum near 310 DU (Fig. 3). Earlier, in June 5-10, total ozone values reached 340-350 DU. In the following days, high ozone conditions recovered and were observed till June 25 . Wind directions on different heights are evident from back trajectories NOAA ARL HYSPLIT data (Draxler and Rolph 2015). For example, maps for June 13 when air mass with products of oil-burning arrived to Kyiv site from southwest are presented in Fig. 4.

In that day, almost the same low total ozone values were registered by Aqua-AIRS on a vast area $(\sim 200 \mathrm{x} 800 \mathrm{~km})$ to south-east from Kyiv $\left(50.36^{\circ} \mathrm{N}\right.$, $\left.30.50^{\circ} \mathrm{E}\right)$. The corresponding pattern is shown in Fig. 5 . One of the possible causes for the observed ozone destruction could be in elevation of the oil burning products and organic gases which were used for fire extinguishing.

\section{Conclusions}

Total ozone content and ozone vertical profiles over Kyiv and neighboring area were studied for June 2015. Ozone decrease in June, 13 is indicated with the groundbased (Dobson, FTIR) and satellite (AIRS, OMI) data series. Analysis of back trajectories has demonstrated a change in the predominant wind direction in the troposphere in June 13. The ozone decrease could be partly connected with strong oil burning which lasted near Vasylkiv in June 8-14.

Acknowledgements. The authors thank the administrations of the AVDC Aqua-AIRS and Aura-OMI web sites for the provision of the necessary satellite data of atmosphere soundings. The work was partly supported by the Special Complex Program for Space Research 2012-2016 of the National Academy of Sciences of Ukraine (NASU) and the project PICS 2013-2015 of CNRS and NASU.

\section{References}

Bernstein L.S., Berk A., Acharya P.K., Robertson D.C., Anderson G.P., Chetwynd J.H., Kimball L.M.: 1996, J. Atmosph. Sci., 53, 2887.

Butchart N.: 2014, Reviews of Geophysics, 52, 157 .

Draxler R.R. \& Rolph G.D.: 2015. HYSPLIT (HYbrid Single-Particle Lagrangian Integrated Trajectory) Model access via NOAA ARL READY (http://ready.arl.noaa.gov/HYSPLIT.php). NOAA Air Resources Laboratory, Silver Spring, MD.

Evtushevsky O., Grytsai A., Milinevsky G.: 2014, Remote Sensing Letters, 5, 205.

Herring J.A., Ferek R.J., Hobbs P.V.: 1996, J. Geophys. Research, 101, 14451. 


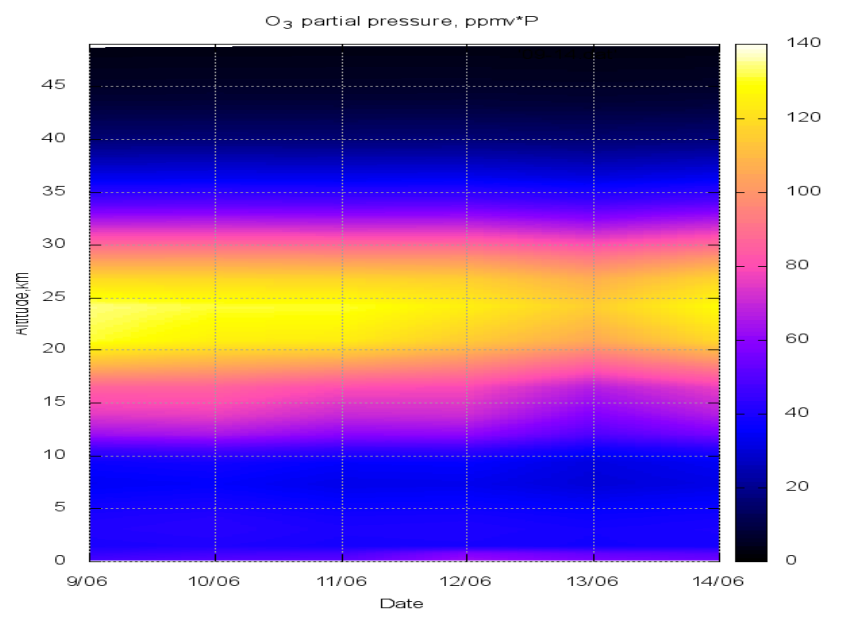

Figure 2: Ozone vertical distribution from FTIR observations, June 9-14, 2015.

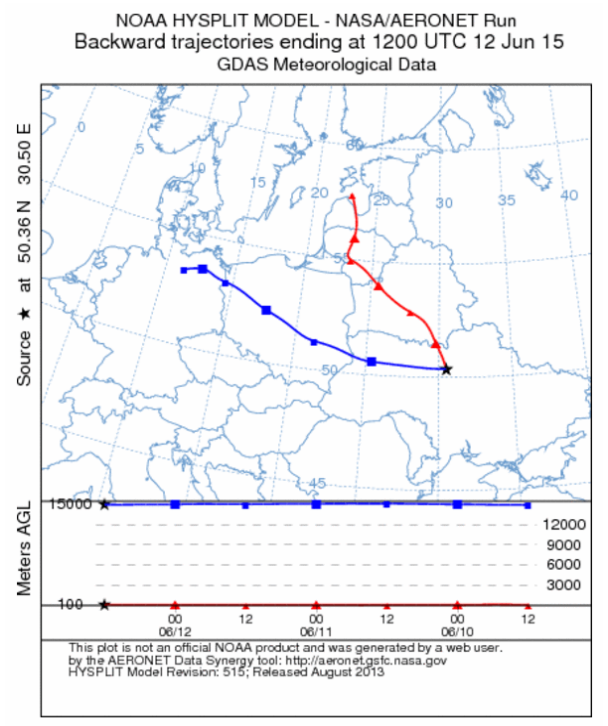

Figure 4: Back trajectories at 12 UTC of both 12 June (left panel) and 13 June (right panel) at the heights of $500 \mathrm{~m}$ (red curve) and $15 \mathrm{~km}$ (blue curve).

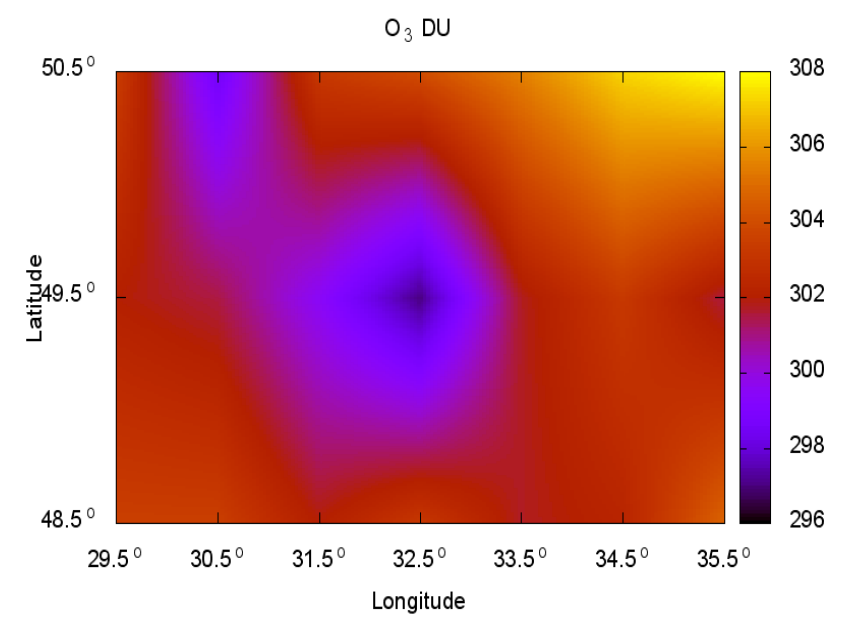

Figure 5: AIRS ozone distribution in June 13, 2015. Total ozone values correspond to the color bar presented in the right part of the figure.
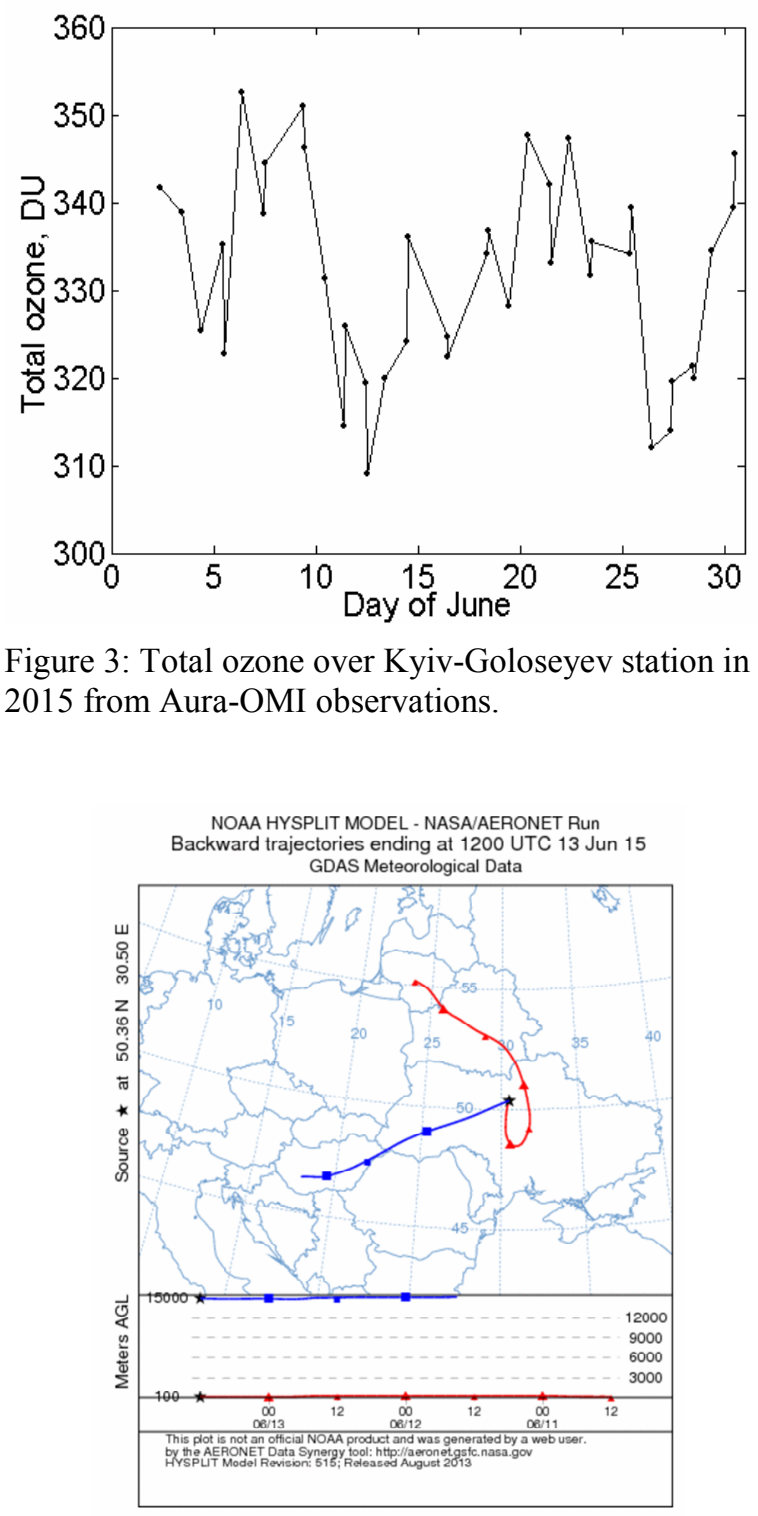

Figure 3: Total ozone over Kyiv-Goloseyev station in June 2015 from Aura-OMI observations.

Herring J.A. \& Hobbs P.V.: 1992, J. Geophys. Res., 97, 14507.

Milinevsky G.P., Danylevsky V.O., Grytsai A.V., Evtushevsky O.M., Kravchenko V.O., Bovchaliuk A.P., Bovchaliuk V.P., Sosonkin M.G., Goloub Ph., Savitska L.Y., Udodov E.V., Voytenko V.P.: 2012, Advanced in Astronomy and Space Physics, $2,114$.

Rothman L. S., Jasqumart D., et al.: 2005, J. of Quantitative Spectroscopy \& Radiative Transfer. 96, 139.

Peters, D.H.W., Gabriel A., Entzian G.: 2008, Annales Geophysicae, 2008, 26, 1275.

Shavrina A.V., Pavlenko Ya.V., Veles A. et al.: 2007, J. of Geophys. Res., 112, D24S45, doi:10.1029/2007JD008787.

Shavrina A.V., Pavlenko Ya.V., Veles A., Sheminova V.A., Syniavskyi I., Sosonkin M.G., Romanyuk Ya.O., Eremenko N.A., Ivanov Yu.C., Monsar O.A., Kroon M.: 2008, Kosmichna nauka i tekhnologiya, 2008, 14, N 5, 85-94 (in Russian). 